\title{
O BIODIESEL NO CONTEXTO JURÍDICO BRASILEIRO
}

Talden Queiroz Farias

\author{
Doutor em Direito da Cidade pela UERJ, doutor em Recursos Naturais pela UFCG e mestre \\ em Ciências Jurídicas pela UFPB. Advogado e professor da UFPB. \\ Email: taldenfarias@gmail.com
}

Arícia Fernandes Correia

Procuradora do Município do Rio de Janeiro e professora da Universidade do Estado do Rio de Janeiro.

Email: ariciacorreia@oi.com.br

\section{RESUMO}

É dentro do contexto atual da crise ambiental que a demanda de energias renováveis adquire toda a sua importância. Nesse sentido, o biodiesel aparece como uma alternativa interessante, especialmente no Brasil, que possui vastas superfícies disponíveis para a agricultura, mão de obra abundante e tecnologia apropriada. Este trabalho tem como objetivo analisar a regulamentação jurídica dos biocombustíveis no Brasil e, mais especificamente, do biodiesel. A despeito de suas vantagens em comparação aos combustíveis fósseis, faz-se necessário ser prudente acerca dos impactos ambientais e sociais desse tipo de combustível. A necessidade de um quadro jurídico renovado que proporciona incitações mais eficazes e uma melhor contemplação da dimensão ecológica desse tipo de combustível constituem o que foi encontrado no presente trabalho. A metodologia utilizada foi a pesquisa bibliográfica e documental, pela leitura de artigos científicos e capítulos de livros, sobretudo documentos oficiais.

Palavras-Chave: Meio ambiente natural; Biocombustíveis; Biodiesel. 
LE BIODIESEL DANS LE CONTEXTE JURIDIQUE BRÉSILIEN

\section{RÉSUMÉ}

C'est dans le contexte courant de la crise environnementale que la quête pour des énergies renouvelables prend toute son importance. En ce sens, le biodiesel apparait comme une alternative intéressante, spécialement au Brésil, qui possède de vastes superficies disponibles pour l'agriculture, de la main d'œuvre abondante et la technologie appropriée. Ce travail a comme objectif de faire une analyse de la réglementation juridique des biocarburants au Brésil et plus spécifiquement du biodiesel. En dépit de ses avantages par rapport aux combustibles fossiles, il est nécessaire d'être prudent sur les impacts environnementaux et sociaux de ce type de carburant. La nécessité d' un cadre juridique rénové qui offre des incitations plus efficaces et mieux contempler la dimension écologique de ce type de carburant est ce qui a été trouvé dans ce travail. La méthodologie utilisée a été la recherche bibliographique et documentaire, en lisant des articles scientifiques, des livres et chapitres de livres, en plus des documents officiels.

Mots-Clés : Environnement Naturel; Biocarburants; Biodiesel. 


\section{INTRODUÇÃO}

É dentro do contexto da crise ambiental, definida como sendo uma situação de penúria dos recursos naturais e de desastres ecológicos de repercussão planetária causados pelas atividades humanas (LEITE, 2003, p. 21-22), que a discussão a respeito das matrizes energéticas renováveis assume uma importância toda particular. Os combustíveis derivados de matéria fóssil, como o petróleo, o gás natural e o carbono mineral, que continuam representando a maior parte da oferta energética mundial (LIMA, 2008, p. 20), são altamente poluentes e contribuem de forma significativa para o aquecimento global, sem contar o fato de que não são renováveis. Como a economia internacional evoluiu bastante nos últimos anos, aumentando consideravelmente a demanda por energia, fenômeno que tende a se desenvolver de forma mais intensa nos países em desenvolvimento, a exemplo da China e da Índia (AGÊNCIA INTERNACIONAL DE ENERGIA 2007, p. 68), parece urgente a busca de uma alternativa que seja viável sob o ponto de vista ecológico, econômico e social.

No Brasil, o biodiesel ${ }^{1}$ é apresentado como uma das grandes alternativas para a substituição dos combustíveis de origem fóssil, quando consideramos a presença de vastas extensões propícias à cultura dessas biomassas e à existência de mão de obra e de tecnologia apropriada. Tratase, efetivamente, de uma oportunidade única para a promoção da redução das desigualdades regionais e sociais e para a representação geológica do país, que se afirma como líder internacional emergente no que diz respeito às energias renováveis e, mais especialmente, os combustíveis (INTERNATIONAL ENERGY AGENCY, 2007, p. 68). A pesquisa da diversificação da matriz energética começa a ocupar um espaço cada vez mais importante na agenda política nacional, a tal ponto que o Programa de Aceleração do Crescimento previu a aplicação de dezessete bilhões e quatrocentos milhões de reais no desenvolvimento e produção de combustíveis renováveis até dezembro de 2015. (SILVA, 2009, p.12).

Entretanto, é importante que estas políticas públicas sejam executadas à luz de uma legislação adequada, considerando-se a importância estratégica do assunto, dado que mesmo as matrizes energéticas

1 De acordo com Pierre Sabliére (2014, p. 1051/1052) um biocombustível é um hidrocombustível líquido obtido a partir de matérias vegetais ou animais, por extração de cadeias de carbonos que estas matérias contêm. O biodiesel é um tipo de biocombustível, como o bioetanol e biogás óleo vegetal. Para Jacques Vernier (2012, p. 87-89), o bioetanol e o biodiesel são as duas espécies mais importantes de biocombustíveis. 
consideradas próprias não estão livres de questionamentos. O biodiesel possui uma estrutura normativa relativamente bem-elaborada, que deve levar em consideração os aspectos de ordem ambiental, econômica e social. O problema reside no fato de que esta legislação é bastante recente, tanto que e se bem que a Lei $n^{\circ}$ 6.938/81 (Política Nacional do Meio Ambiente) nem a Lei $n^{\circ}$ 9.478/97 (Política Energética Nacional), em suas versões originais, não se posicionam sobre esse tema, de tal maneira que essa legislação padece de uma falta de maturidade e de efetividade.

O objetivo desse trabalho é, portanto, o de realizar uma análise da regulamentação jurídica do biodiesel no Brasil, face à intenção de descobrir se a legislação em vigor é adequada e se existe uma integração das políticas públicas desse setor. Nessa linha de raciocínio, será estudado o enquadramento ambiental desta modalidade de combustível na Política Energética Nacional, tomando-se como referência a doutrina especializada e a legislação ambiental e energética brasileira. Serão também observadas as possibilidades de estímulo à produção e promoção do uso de biodiesel por meio da política urbana, apesar de a competência para ajustar e regular ${ }^{2}$ o setor ser federal.

\section{BIODIESEL}

De acordo com Assis e Zucarelli, o biodiesel é um «combustível líquido derivado de biomassa renovável, produzido a partir de diferentes matérias-primas, de rícino, de purgueira, de palma, de algodão, de babaçu, entre outras; de gorduras animais; e de óleos usados.» (ASSIS; ZUCARELLI, 2007, p. 44). A alínea XXV do artigo $6^{\circ}$ da Lei n ${ }^{\circ}$ 9.478/976 classifica o biodiesel como o "combustívevel derivado de biomassa renovável para uma utilização em motores de combustão interna com arranque por compressão ou, de acordo com a regulamentação, para a produção de outros tipos de energia, que possam substituir parcialmente ou totalmente os combustíveis de origem fóssil."

Em 1900, Rudolph Diesel apresentou na Exposição Universal de Paris, na França, um motor desenvolvido sob seus cuidados, que funcionava

2 No Brasil, a disciplina das atividades econômicas lato sensu - neste caso, os serviços públicos anteriormente monopolizados pelo Estado - que foram abertos à iniciativa privada na década de 90 do século passado - são objeto de um novo campo do direito administrativo, denominado direito de regulação. Para uma ampla visão da lei de regulamentação na ordem jurídica brasileira, é preciso consul$\operatorname{tar}$ ARAGÃO, 2002. Da mesma forma, para Frison-Roche, "o direito de regulamentação econômica é implantado, em grande parte nas ruínas de uma organização econômica construída em torno de monopólios estaduais responsáveis pelos serviços públicos e na perspectiva da globalização. (FRISON-ROCHE, 2004, 7) 
à base de óleo de amendoim. Apesar de o projeto, na época, não ter podido demonstrar sua viabilidade econômica, razão pela qual foi abandonado, foi, pelo menos, a primeira experiência com o biodiesel da qual se tem conhecimento.

Em 1937, Charles Georges Chavanne obtém em Bruxelas, Bélgica, o registro do primeiro depósito de patente e, no ano seguinte, apresenta a primeira patente comercial do biodiesel (MAIA, 2012, p.19). A técnica utilizada era a de mesclar o óleo vegetal de palma e o etanol, de modo a obter o biodiesel por meio da transesterificação, que é ainda hoje o método mais usual para a conversão de triglicérides em biodiesel. Segundo Assis e Zucarelli, esta técnica «consiste em uma reação química em meio alcalino, em que se promove a reação dos óleos vegetais ou gorduras animais e um álcool (etanol ou metanol)» (ASSIS; ZUCARELLI, 2007, p. 45). Embora em 1938 o biodiesel tenha sido utilizado pela primeira vez em uma linha comercial de autocarros em Bruxelas e Louvain, trata-se somente de uma experiência isolada que não teve nenhum desenvolvimento posterior.

Provavelmente, é o contexto de penúria que se instalou justamente antes e durante a Segunda Guerra Mundial (1939-1945), que impulsionou inúmeros países envolvidos por esse drama a buscar alternativas nos combustíveis derivados do petróleo e os óleos vegetais revelaram-se como uma real alternativa. A prova é a interdição no Brasil, durante este período, de exportar as sementes de algodão, planta mais apropriada para a obtenção do óleo in natura (MAIA, 2012, p. 19). Entretanto, após o fim do conflito, devido a diversos entraves financeiros e tecnológicos, as pesquisas foram, mais uma vez, deixadas de lado.

No Brasil, as primeiras experiências com o biodiesel foram realizadas por ocasião dos testes efetuados nos anos 1920 pelo Instituto Nacional de Tecnologia (INT), que praticava experiências com combustíveis renováveis visando desenvolver recursos energéticos alternativos (SILVA; TRENTINI, 2009, p. 28). Nos anos sessenta, o Conde Francisco Matarazzo obteve o biodiesel em suas indústrias, ao tentar extrair óleo a partir do grão do café (LIMA, 2008, p. 108). Todavia, estas diversas iniciativas foram pouco importantes e isoladas, não proporcionando qualquer resultado provável.

Devido às crises petroleiras de 1973 e 1979, ligadas ao fenômeno da regulação da circulação da produção pelos países produtores, que engendrou um aumento do preço do barril, a questão dos combustíveis derivados de óleos vegetais e de gorduras animais ressurgiu, ocupando 
destaque no centro do cenário. Embora os maiores esforços fossem concentrados sobre o álcool, mais no plano nacional do que internacional, houve igualmente repercussões sobre as discussões e as pesquisas sobre o biodiesel. Nessa época, o INT, o Instituto de Pesquisas Tecnológicas (IPT) e a Comissão Executiva do Plano de Cultura Cacaueira (CEPLAC) começaram a desenvolver pesquisas sobre a utilização de óleos vegetais como combustível, tendo como um dos programas mais interessantes o DENDIESEL, visando produzir o biodiesel a partir do óleo de dendê (MEIRELLES, 2013, P. 13).

Com este mesmo espírito, o Regime Militar Brasileiro lança o Programa Nacional do Álcool (Proálcool), por meio do Decreto $\mathrm{n}^{\mathrm{o}}$ $76.593 / 75$, visando criar alternativas reais para a substituição, em grande escala, da essência. O referido decreto previa a possibilidade de utilização da mandioca ou de qualquer outro produto para a obtenção de combustível automóvel, de modo a que, ao menos teoricamente, o biodiesel pudesse também ser capaz de receber as mesmas medidas de incitação governamental que as atribuídas ao Pro-Álcool. Entretanto, pelo fato de um retorno sobre investimento consideravelmente mais importante por hectare plantado de cana-de-açúcar, somente a produção de álcool seria destinada a uma posição de liderança em face dos Poderes Públicos e do mercado, em consonância com o próprio nome do programa (FARIAS, 2010, p.125)..É inegável que a força já secular do setor econômico açúcar-álcool, que ambicionava ganhar um espaço no segmento energético, contribuiu para esse novo quadro, de tal manera que essa dimensão política não pode ser ignorada.

É nesse contexto de crise petroleira que a Universidade Federal do Ceará (UFC) criou, em 1978, o Núcleo de Recursos Não Convencionais de Energia, com o objetivo de desenvolver fontes energéticas alternativas, o que incluía a pesquisa sobre a biomassa (FERREIRA, 2010, 92-93). Em 1980, o professor Expedito Parente, da UFC, requereu ao Instituto Nacional de Propriedade Industrial (INPI) o registro de patente de duas licenças concernantes ao biodiesel; em 1983, a licença PI no 8007957 foi concedida, referindo-se ao «Processo de produção de combustíveis originados de frutas ou de grãos oleaginosos»».

Em 1983, o Governo Federal lançou, por meio do Secretariado de Tecnologia Industrial, o Programa Nacional de Óleos Vegetais (OVEG), que realizou testes com os óleos vegetais transesterificados, puros ou mesclados ao diesel, numa proporção de $30 \%$, em veículos que vieram a percorrer mais de um milhão de quilômetros (COSTA NETO; ROSSI; 
ZAGONEL; RAMOS, 2000, p. 534). Os caminhões, ônibus e tratores apresentaram resultados satifatórios, principalmente porque os motores não sofreram adaptações particulares para serem alimentados em diesel, o que provou, portanto, a viabilidade técnica do combustível alternativo (COSTA NETO; ROSSI; ZAGONEL ; RAMOS, 2000, p. 534-535). Apesar disso, os altos custos de produção em comparação ao óleo diesel não permitiram ao biodiesel integrar o mercado de combustíveis nesse exato momento (MEIRELLES, 2013, P. 13).

Em função do aumento dos preços do diesel nos anos 1990, o Governo Federal começou a demonstrar um certo interesse no desenvolvimento do biodiesel como real alternativa energética e lançou, em 2002, por intermédio do Ministério de Ciências e Tecnologias, o Programa Brasileiro de Desenvolvimento Tecnológico de Biodiesel (Probiodiesel), por intermediação da Portaria $\mathrm{n}^{0} 702$, visando promover o desenvolvimento científico e tecnológico do biodiesel a partir de ésteres etílicos de óleos vegetais puros ou residuais. Em 2003, o Ministério das Minas e Energias lança o Programa Combustível Verde, estabelecendo um objetivo de produção de um milhão e quinhentos mil barris de biodiesel e insistindo, a partir de então, na promoção do emprego e do salário em zona rural (SILVA; TRENTINI, 2009, p. 28-29).

Em 2004, o Governo Federal lançou o Programa Nacional de Produção e Utilização de Biodiesel (PNPB) do Ministério da Agricultura, Pecuária e Abastecimento (MAPA), do Ministério das Minas e Energia (MME) e de outros organismos federais, na tentativa de criar um programa mais completo que o Probiodiesel ${ }^{3}$. Apesar de se tratar de uma política essencialmente energética, o Governo Federal buscou estabelecer, nesse meio, uma série de objetivos de ordem ambiental, econômica e social, cujas diretrizes principais seriam a implantação de um programa capaz de promover a inclusão social, a garantia de estoque, o preço competitivo, a qualidade e a diversidade de fontes oleaginosas e de regiões produtoras (NODARI, 2010, p. 57).

Entretanto, a Lei $n^{0} 11.097 / 05$ representou, realmente, um elemento de referência no domínio jurídico do biodiesel, consolidando o PNPB, ao permitir a introdução deste último na matriz energética brasileira e ao alterar a Lei ${ }^{\circ} 9.478 / 97$. O «caput» do artigo $2^{\circ}$ da Lei ${ }^{\circ}$

\footnotetext{
3 A entrada em vigor, em 16 de fevereiro de 2005, do Protocolo de Kyoto torna ainda mais pertinentes por todo o mundo as ações foram realizadas no setor da energia, a fim de reduzir as emissões de gás com efeito estufa e de diminuir a dependência energética. Para ver no contexto francês..., consultar LONDON, 2005, étude 30.
} 
11.097/05 fixou uma porcentagem obrigatória de 5\% de adição mínima de biodiesel ao óleo diesel oferecido ao consumidor final, estendida a todo o território nacional. Esse fato representou um ponto marcante na Política Energética Nacional, porque esta foi a primeira medida jurídica efetiva de grande impacto na inclusão econômica de um biocombustível diferente do álcool ${ }^{4}$.

É necessário destacar a versatilidade do biodiesel que pode tanto ser misturado aos derivados do petróleo - já que ele é passível de ser utilizado em um motor diesel sem que este último sofra algum tipo de adaptação particular (CUNHA, 2008, p. 449) - quanto substituir completamente esses mesmos derivadors. Isso significa, portanto, que o biodiesel, ao consolidar atualmente seus títulos de nobreza como uma opção futura, se posiciona também como uma via possível para prolongar a esperança de vida do setor petroleiro.

Com efeito, o PNPB foi pensado igualmente como uma forma de garantir a autonomia para o consumo nacional de óleo diesel (ASSIS; ZUCARELLI, 2007, p. 47), de maneira a que o biodiesel pudesse ser também um combustível autõnomo mas também um combustível acessório no setor petroleiro. Isso quer dizer, portanto, que a euforia em torno da exploração do «pré-sal»» não representa um obstáculo, mesmo que seu sucesso ou seu fracasso possa contribuir para o desenvolvimento

\footnotetext{
4 Dentre as vantagens desse combustível, Rubens Onofre Nodari destaca os seguintes pontos: "É uma energia renovável, constituída de carbono, que é capturada por fotossíntese realizada pelas plantas que, por sua vez, produzem e estocam óleos vegetais, ou mesmo pelo anabolismo dos animais que produzem gorduras"; É uma alternativa econômica ao combustível de origem fóssil, que é limitado; “Quando de sua combustão, ele apenas produz água e gás carbônico, contribuindo assim para evitar a emissão de gás com efeito de estufa"; É menos poluente que o óleo diesel, já que não possui enxofre (S) em sua estrutura molecular e, em consequência, não gera compostos secundários sulfurados indesejáveis, que são elementos contaminantes da atmosfera terrestre"; Ele irá contribuir para o aumento do número de empregos no setor primário"; Ele oferece uma alternativa de autossuficiência para a agricultura familiar, porque o agricultor que produz o óleo vegetal ou o álcool poderá utilizá-lo como é ou transformá-lo em combustível. É uma estratégia de redução de custos da produção agrícola, se for utilizada localmente, já que o óleo vegetal ou o álcool não necessitam percorrer milhares de quilômetros, nem são submetidos a imposto como os derivados do petróleo. "É um excelente combustível que aumenta a durabilidade de vida do motor e, se consideramos suas características fisicoquímicas, talvez mescladas com o diesel ; ele possui um índice de cetaneo mais elevado que o óleo diesel, possibilitando um maior torque automotor que ele utiliza"; Segundo a política agrícola encontrada pelo governo, ele poderá ser fonte de emprego e de salário, evitando ou minimizando a migração de populações das zonas rurais para as zonas urbanas. (NODARI, 2010, p. 57-58).

5 Pré-sal é o nome dado às primeiras reservas de hidrocombustíveis no seio de rochas calcárias que se localizam sob a camada de sal. É o óleo (petróleo) descoberto em camadas de 5 a 70000 metros de profundidade sob o nível do mar. Estas reservas se propagam sobre cerca de 800 quilômetros de comprimento para 200 quilômetros de largura e vai do litoral do Estado de Santa Catarina ao literal do Estado do Espírito Santo. A professora Angela Moulin Penalva Santos (2015), que faz parte também da pesquisa sobre energias Renováveis, Descentralização e o Papel das Entidades Federais, escreveu uma análise econômica a respeito desse fenômeno, no qual verifica uma diminuição de estímulo à produção das energias renováveis no Brasil, exatamente após a descoberta do pré-sal. (na imprensa).
} 
de maneira mais ou menos importante da indústria do biodiesel em um futuro não tão distante.

Enfim, se é verdade que os custos do biodiesel continuam elevados quando comparados aos do diesel comum, parece judioso especificar que esta diferença tende a diminuir em função do aumento da escala de produção desse último. O agravamento contínuo da problemática ambiental tende também, e cada vez mais, a reforçar o espaço dos combustíveis renováveis; esses últimos mostram mais ainda os ativos ao nível social, os quais não são negligenciáveis. As reflexões em torno da cidade durável são responsáveis também pela ideia de que o biodiesel possa ser uma nova alternativa para melhorar a qualidade de vida nessa cidade. Um relatório sobre os «Biofuels para Transportação», produzido em 2006 pelo World Watch Institute ( 2006, p. 38), provou a posição de vanguarda do Brasil nessa matéria e listou suas vantagens, como a segurança energética, a redução da poluição local e as emissões de gás com efeito estufa, em relação aos quais as regras urbanísticas podem estar a pleno serviço. ${ }^{6}$

\section{REGULAMENTAÇÃO JURÍDICA DO BIODIESEL}

A mais importante norma jurídica brasileira no setor da energia é a Lei ${ }^{\circ}$ 9.478/97, que trata da Política Energética Nacional e das atividades relativas ao monopólio do petróleo, além de instituir o Conselho Nacional de Política Energética (CNPE) e a Agência Nacional do Petróleo (ANP). Esta lei foi criada para estabelecer a regulamentação jurídica da exploração das fontes e recursos energéticos do país, representando, de fato, sua principal referência legal. ${ }^{7}$

Entretanto, após sua redação original, a regulamentação do setor de petróleo e de gás natural apareceu como o principal elemento da lei, em

\footnotetext{
6 Em 2000, a Comissão Europeia avança com um objetivo de substituição daquele momento, até 2020, de $20 \%$ do diesel e da essência utilizada no transporte rodoviários por combustíveis de substituição. Porém, a iniciativa cabia também ao gás natural e hidrogênio. De acordo com Bernadette Le Baut-Ferrarese e Isabelle Michallet, "de fato, é a diretriz europeia de biocombustíveis utilizados de 2003 que foi a primeira a editar verdadeiros objetivos quantitativos concernentes aos biocombustíveis utilizados nos veículos [diante da constatação de que] "os transportes rodoviários representam cerca de $30 \%$ do consumo energético final da União europeia e cerca de $20 \%$ do total de emissões de gás com efeito estufa" em seu território (BAUT-FERRARESE, 2008-2012, p. 465). De acordo com Sablière (2014, p. 1057), na França"os biocombustíveis se beneficiam de um sistema tributário destinado a favorecer seu desenvolvimento em conformidade com as diretrizes europeias."

7 A Lei Federal n. 9.427/1996, por sua vez, regulou o setor das energias elétricas e criou também a Agência das Energias Elétricas (ANEEL), uma autarquia sob regime especial, que regula o setor, principalmente as concessões, permissões e autorizações de exploração respectiva. Contudo, há pouco interesse - para não se dizer nenhum, uma vez que a exploração de energia hidrálica é regulada - pelas energias alternativas.
} 
detrimento dos outros segmentos que compõem nossa matriz energética (ANTUNES, 2012, p. 1003-1004). Isso é tanto verdade que a maior parte dos estudos sobre esta norma acentua simplesmente esses dois tipos de combustíveis (COSTA, 2007, p. 23-29 ; GARCIA, ROCHA, 2005, p. 257287 ; LEITE, GUTMAN, 2007, p. 31-39). A explicação é que a referida lei surgiu no contexto da Emenda Constitucional $n^{\circ}$ 09/95, que cassou o monopólio da União sobre as atividades decorrentes da indústria do petróleo e delegou à lei ordinária a regulamentação da matéria, alterando o artigo 177, $\S \S 1^{\circ}$ e $2^{\circ}$ da Constituição da República ${ }^{8}$.

A respeito disso, a lei não esqueceu de fazer referência aos combustíveis alternativos em sua redação original, ao determinar no artigo $1^{\circ}$, IV e VIII, respectivamente, que a Política Energética Nacional visará à proteção do meio ambiente natural e à utilização de fontes alternativas de energia com a valorização econômica dos materiais disponíveis. Por outro lado, o artigo 2, III estabelece como uma das atribuições do CNPE a revisão periódica das matrizes energéticas utilizadas nas diversas regiões do país, em cujo âmbito as fontes alternativas deverão também ser levadas em consideração.

Trata-se de uma referência indireta ao biodiesel, e aos combustíveis de modo geral, considerando que todos os combustíveis alternativos seriam envolvidos. Todavia, é importante destacar que isto não provocou efeitos especificamente práticos, explicando-se pelo fato de que o tratamento legislativo do assunto era inicialmente disperso e superficial.

É somente com a Medida Provisória $n^{\circ} 214 / 04^{9}$, convertida em Lei $n^{\circ} 11,097 / 05$, tratando da introdução do biodiesel na matriz energética brasileira, que temos legislado de maneira mais detalhada sobre esse assunto. A partir desta lei, o biodiesel passou a ocupar um espaço mais

8 Art. 177. Constituem um monopólio da União: I - a busca e exploração de depósitos de petróleo e de gás natural e de outros carbonatos fluidos; II - o refinamento do petróleo nacional ou estrangeiro; III - a importação e exportação dos produtos e derivados básicos resultantes das atividades previstas nos dispositivos anteriores; IV - o transporte marítimo do petróleo bruto de origem nacional ou de derivados básicos de petróleo produzidos no país, assim como o transporte, por meio de tubulações e de gasodutos, de petróleo bruto, de seus derivados e de gás natural de toda origem: $(\ldots) \S 1^{\circ} \mathrm{A}$ União poderá concluir contratos com empresas estatais ou privadas para a realização das atividades previstas nas disposições I a IV deste artigo, observando as condições estabelecidas pela lei. $\quad \S 2^{\circ} \mathrm{A}$ lei à qual se refere o $\S 1^{\circ}$ tratará de: I - a garantia da aquisição dos derivados de petróleo em todo o território nacional; II - as condições de contrato de fornecimento; III - a estrutura e as atribuições do órgão regulador do monopólio da União (...).

9 No direito constitucional brasileiro, a Medida Provisória (MP) é um ato próprio do presidente da república, tendo força de lei sem a participação do Poder Legislativo, que só será chamado a discutir essa medida posteriormente, tendo a competência de converter a Medida Provisória em lei ou não, hipótese em que se torna necessário disciplinar os relatórios jurídicos que foram realizados até à liberação para a não conversão. Os critérios pré-requeridos da MP, de acordo com o artigo 62 da Constituição Federal, são a urgência e a pertinência. 
substancial na Polítia Energética Nacional, porque ela modificou vários pontos da Lei n ${ }^{\circ}$ 9.478/97, alterando o nome do ANP, que se tornou Agência Nacional do Petróleo, do Gás Natural e dos Biocombustíveis. Embora não se tratando de uma questão terminológica, a importância desta alteração não pode ser negligenciada, supondo-se que ela simbolize a intenção dos Poderes Públicos de priorizar igualmente esta matriz energética e de não reduzir a política pública nacional aos combustíveis fósseis. ${ }^{10}$

Nesta situação, parece evidente que a agência reguladora responsável pela indústria do petróleo começou a regular, na mesma ocasião, as atividades econômicas ligadas ao biodiesel e aos biocombustíveis de modo geral. A Lei $\mathrm{n}^{\circ}$ 11.097/05 mudou igualmente a Lei $\mathrm{n}^{\circ}$ 9.847/99, que trata do controle das atividades relativas ao abastecimento nacional de combustíveis e estabelece sanções administrativas no caso de desrespeito às determinações legais; ela permitiu que a produção, importação, exportação, armazenamento, estocagem, distribuição, revenda e comercialização de biodiesel fossem igualmente objeto do controle público.

As infrações administrativas ligadas ao biodiesel e aos biocombustíveis de modo geral passaram a ser punidas por meio de sanções administrativas previstas pela Lei $\mathrm{n}^{\circ}$ n.9.847/97, cuja aplicação só pode ser realizada pelo setor de controle da ANP. Paralelamente, as três pequenas penalidades impostas pelo Ministério da Agricultura, Pesca e Abastecimento (MAPA) deixaram de ser aplicadas à indústria dos biocombustíveis que são classificados no inciso do artigo $6^{\circ}$ da Lei $\mathrm{n}^{0}$ 9.478/97 como «o conjunto das atividades econômicas ligadas à produção, importação, exportação, transferência, transporte, estocagem, comercialização, distribuição, avaliação da conformidade e certificação da qualidade dos biocombustíveis» e as novas penalidades que prevaleceram foram, então, as seguintes ${ }^{11}$.

10 Convém ratificar que, apesar de ser da competência da União disciplinar a energia, também é possível aos legisladores municipais estimular a produção de biodiesel sob uma política de durabilidade da cidade, seja por medidas extrafiscais seja por leis urbanísticas propriamente.

11 Art. $2^{\circ}$. Os infratores das disposições desta Lei e das outras normas pertinentes ao exercício de atividades relativas à indústria do petróleo, à indústria dos biocombustíveis, ao abastecimento nacional de combustíveis, ao Sistema Nacional de Estoque de Combustíveis e ao Plano Anual de Estoques Estratégicos de Combustíveis estarão sujeitos às sanções administrativas seguintes, sem prejuízo das sanções ou penalidades de natureza civil e penal aplicáveis: I - Multa; II - apreensão de bens e produtos; III - perda de produtos apreendidos; IV - anulação do registro do produto na ANP; V - suspensão do fornecimento de produtos; VI - suspensão temporária, total ou parcial de funcionamento de estabelecimento ou de instalação; VII - anulação de registro de estabelecimento ou de instalação; VIII - revogação de autorização para o exercício de atividade. Parágrafo único. As sanções previstas nesta Lei poderão ser aplicadas cumulativamente.

Art. $3^{\circ}$. A pena de multa aplicada por ocasião do cometimento da infração, nos limites seguintes: I - exercer uma atividade relativa à indústria do petróleo, à indústria de biocombustíveis, ao abastecimento 
nacional de combustíveis, ao Sistema Nacional de Estoques de Combustíveis e ao Plano Anual de Estoques de Combustíveis, sem registro prévio nem autorização exigida pela legislação em vigor: Multa - de R \$ 50.000,00 (cinquenta mil reais) a R 200.000 (duzentos mil reais); II - importar, exportar ou comercializar petróleo, gás natural, seus derivados e biocombustíveis em quantidade ou especificação diferente da autorizada, bem como dar ao produto uma destinação não permitida ou diferente da autorizada, segundo a forma prevista pela legislação em vigor :Multa - de R \$ 20.000,00 (vinte mil reais) a 5.000.000,00 (cinco milhões de reais);

III - não respeito aos preços fixados pela legislação em vigor para a venda de petróleo, de seus derivados básicos e de seus produtos, de gás natural e de condensado, e de álcool etílico sob forma de combustível: Multa - de 5.000,00 (cinco mil reais) a 1.000.000,00 (um milhão de reais); IV - não registrar ou não preencher os livros ou outros documentos de acordo com a legislação em vigor ou a não apresentá-los, quando sua solicitação é feita: Multa - de 5.000,00 (cinco mil reais) a 10.000,00 (dez mil reais); V - fazer declarações ou dar informações erradas, falsificar, adulterar, tornar inutilizável, simular ou alterar registros e transferências de escrituras e de outros documentos exigidos pela legislação em vigor: Multa - de 20.000,00 R \$ (vinte mil reais) a 1.000.000,00 (um milhão de reais); VI - não apresentar, sob a forma e prazos estabelecidos pela legislação em vigor ou na sua falta, num espaço de 48 (quarenta e oito) horas, os documentos provando a autenticidade de produção, importação, exportação, refinamento, valorização, tratamento, transformação, transporte, transferência, entrepostagem, estocagem, distribuição, revenda, destinação e comercialização de petróleo, de gás natural, de seus derivados e de biocombustíveis: Multa - de R\$ 20.000,00 (vinte mil reais) a 1.000.000,00 (um milhão de reais);VII - fazer declarações ou dar informações erradas, falsificar, adulterar, tornar inutilizável, simular ou alterar registros e transferências de escrituras e de outros documentos exigidos pela legislação em vigor, a fim de receber indumentos de valores a título de benefício fiscal, subvenção, reembolso de frete, despesas de transferência. De estocagem e de comercialização: Multa - de 500.000,00 R\$ (quinhentos mil reais) a 5.000.000,00 (cinco milhões de reais); VIII - não respeitar as normas de seguridade previstas para o comércio ou estocagens dos combustíveis, colocando em perigo diretamente e de maneira imediata a vida, a integridade física ou a saúde, o patrimônio público ou privado, a ordem pública ou o abastecimento nacional regular de combustíveis: Multa - de 20.000,00 R\$ (vinte mil reais) a 1.000.000,00 (um milhão de reais);IX - construir ou operar as instalações ou equipamentos necessários ao exercício das atividades concernentes a esta lei em desacordo com a legislação em vigor: Multa - de 5.000,00 R\$ (cinco mil reais) a 2.000.000,00 (dois milhões de reais); X - guardar, ocultar produtos: Multa - de 50.000,00 R\$ (cinquenta mil reais) a 1.000.000,00 (um milhão de reais);XI - importar, exportar e comercializar petróleo, gás natural, seus derivados e biocombustíveis, além das especificações técnicas, com vícios de qualidade ou de quantidade, compreendidos aí aqueles que provêm da disparidade com as indicações inscritas no recipiente, na embalagem ou etiqueta, que os façam impróprios ou inadaptados para o consumo ao qual são destinados ou que diminuam o valor: Multa - de 20.000,00 R \$ (vinte mil reais) a 5.000.000,00 (cinco milhões de reais);XII - não comunicar informações para o cadastro ou alterações de informações já cadastradas no organismo competente, a alteração da razão social ou do nome fantasia e do endereço, seguindo as condições estabelecidas; Multa - de 5.000,00 (cinco mil reais) a 10.000,00 (dez mil reais);XIII - ocultar, violar ou inutilizar um selo, um carimbo ou uma marca de autenticação, empregada por ordem da fiscalização, para identificar ou fechar um estabelecimento, uma instalação, um equipamento ou um canteiro de obras: Multa - de $50.000,00$ (cinquenta mil reais) a 1.000.000,00 (um milhão de reais);XIV - desviar, deslocar, alterar ou vender um produto estocado em um estabelecimento ou uma instalação suspensa ou interditada nos termos dessa Lei; Multa - de 500.000,00 (quinhentos mil reais) a 2.000.000,00 (dois milhões de reais);XV - cessar de fornecer aos consumidores informações previstas na legislação em vigor ou fornecê-las em desacordo com esta mesma legislação; Multa - de 5.000,00 (cinco mil reais) a 50.000,00 (cinquenta mil reais);XVI - não ter respeitado uma notificação para a apresentação de documentos ou para uma demanda de determinação exigíveis pela legislação em vigor, visto que uma tal obrigação não representa, por si mesma, um fato já definido como infração na presente lei: Multa - de 5.000,00 (cinco mil reais) a 100.000,00 (cem mil reais);XVII - não poder provar uma orientação ou uma entrega de manuais, de documentos, de formulários e de equipamentos necessários segundo a forma definida pela legislação em vigor: Multa - de 10.000,00 (dez mil reais) a 500.000,00 (quinhentos mil reais);XVIII - não dispor de equipamentos necessários à verificação da qualidade, da quantidade estocada e comercializada dos produtos derivados do petróleo, do gás natural e de seus derivados, e dos biocombustíveis: Multa - de $5.000,00$ (cinco mil reais) a 50.000,00 (cinquenta mil reais);XIX - não enviar, sob a forma e o espaço de tempo estabelecido na legislação em vigor, as informações mensais sobre as atividades: Multa - de 20.000,00 (vinte mil reais) a 1.000.000,00 (um milhão de reais). 
É importante notar que a Lei no $9.478 / 97$, mesmo após as alterações da Lei $n^{\circ} 11.097 / 05$, não fazia nenhuma alusão direta a outras modalidades de biocombustíveis que não fosse o biodiesel. A importância dada por essa mesma lei ao biodiesel pode ser justificada pela falta de pesquisa e de planejamento comparada aos outros tipos de biocombustíveis, mas não em relação ao álcool, que é bem mais antigo dentro da matriz energética brasileira que o biodiesel ou qualquer outra espécie de biocombustível.

Com essa mudanças, o nome "biodiesel" começou a ser citado com mais frequência nessa lei que o próprio nome "biocombustível", fato minimamente contraditório, considerando-se que esse último representa uma categoria, ao passo que o primeiro é um ingredinte. Na realidade, esse quadro foi modificado com a Lei ${ }^{\circ} 12490 / 2011$, que introduziu inúmeras referências aos biocombustíveis.

Sem dúvida, o ponto mais importante da Lei $n^{0} 11.097 / 05$, proveniente da alteração da Lei $n^{\circ} 9.478 / 97$, foi a introdução no caput de seu art. $2^{\circ}$ de uma porcentagem mínima obrigatória de $5 \%$ de adição de biodiesel com óleo diesel posto à disposição do consumidor final e em todo ponto do território nacional. O prazo para a aplicação dessa porcentagem foi fixado em oito anos após a publicação desta lei, mesmo que o combustível devesse já, ao fim de três anos, apresentar uma porcentagem mínima de $2 \%$, em conformidade com a determinação do $\S 1^{\circ}$ da disposição citada anteriormente. É claro que esta obrigação foi certamente a medida mais concreta para a disseminação do biodiesel na matriz energética brasileira.

Observa-se que, após $1^{\circ}$ de janeiro de 2010, o óleo diesel nacional contém já $5 \%$ de biodiesel, em conformidade com a Resolução $n^{\circ}$ 6/2009 do CNPE, a fim de que o objetivo fosse alcançado bem antes do processo legal, corroborando, assim, o sucesso da PNDB. O Brasil é realmente um dos líderes mundiais na fabricação e no consumo de biodiesel, tendo atingido a produção de 2,4 bilhões de litros e uma capacidade produtiva de 5,8 bilhões de litros (AGÊNCIA NACIONAL DO PETRÓLEO, GÁS NATURAL E BIOCOMBUSTÍVEIS 2013). Prova disso é que a porcentagem pode ser aumentada a todo momento para atender o valor de 6 ou $7 \%$, podendo chegar a $20 \%$ até 2020 . A previsão do MAPA é de que em 2035 o país possa produzir um volume aproximado de 50 bilhões de litros de biodiesel por ano, apenas para o mercado interior (ASSIS; ZUCARELLI, 2007, p. 49), o que significa dizer que as expectativas do Governo Federal são realmente promissoras.

Alguns meses após a publicação da Medida Provisória nº 214/04, 
uma outra foi publicada, a Medida Provisória n 227/04, que foi transformada em lei (Lei $n^{\circ} 11.116$ ?2005), tratando do registro especial do produtor ou importador do biodiesel no Secretariado da Receita Federal do Ministério das Finanças, e da incidência da contribuição para o PIS/PASEP e a COFINS sobre as receitas provenientes da venda desse produto. O objetivo dessa operação foi o de conseguir que o biodiesel pudesse ser competitivo no mercado. Com efeito, há pelo menos seis tipos de impostos diferentes que influem sobre os combustíveis brasileiros, tais como a Contribuição de Intervenção no Domínio Econômico (CIDE), o Programa de Integração Social (PIS), a Contribuição para o Financiamento da Seguridade Social (COFINS) e o Imposto sobre a Circulação de Mercadorias e a Prestação de Serviços de Transporte Interestadual e Intermunicipal e de Comunicação $(\mathrm{ICMS})^{12}$

Assim, a intenção é diminuir o peso das contribuições fiscais que pesam sobre a produção de biodiesel e que podem ser reduzidas completamente, no caso dos integrantes da agricultura familiar das regiões Norte, Nordeste e Semiárido abrangidos pelo Programa Nacional de Consolidação da Agricultura Familiar (PRONAF) e dos detentores da concessão de utilização do «Selo combustível social», que consiste em um conjunto de medidas específicas visando incitar à inclusão social da agricultura nessa cadeia de produção. Para regulamentar a matéria, o Decreto $n^{\circ}$ 5297/04 foi publicado; trata dos coeficientes de redução das porcentagens respectivas das contribuições mencionadas anteriormente e dos termos e condições para a utilização dessas porcentagens diferenciadas ${ }^{13}$.

\footnotetext{
12 Em matéria de regulação urbanística extrafiscal do solo, a diminuikção do Imposto de Construção e Territorial Urbano, da competência das Municipalidades brasileiras, para os imóveis ligados, mesmo que indiretamente,e la compétence des Municipalités brésiliennes, pour les immeubles liés, ainsi que indirectement, à rede de produção do biodiesel ou por aquele em que o combustível é vendido pode ser uma outra alternativa de extrafiscalidade para o serviço dos combustíveis não fósseis e da cidade durável.
}

13 Art. $2^{\circ}$. Foi instituído um timbre "Combustível Social”, que será concedido ao produtor de biodiesel, que permite :I - promover a inclusão social dos agricultores familiares participantes do Programa Nacional de Consolidação da Agricultura Familiar (PRONAF) que fornececem a matéria-prima;II - provar a regularidade frente ao Sistema de Cadastro Unificado de Fornecedores - SICAF. $\S 1^{\circ}$ Para promover a inclusão social dos agricultores familiares, o produtor de biodiesel deve:I - adquirir do agricultor familiar uma parcele não inferior a uma porcentagem a ser definida pelo Ministério do Desenvolvimento Agrário, a matéria-prima para a produção de biodiesel;II - celebrar contratos com os agricultores familiares, especificando as condições comerciais que garantam uma renda e os prazos compatíveis com a atividade, conforme as condições a serem estabelecidas pelo Ministério do Desenvolvimento Agrário;III - assegurar uma assistência e uma formação técnica aos agricultores familiares. $§ 2^{\circ}$ A porcentagem definida pelo inciso I do $\S 1^{\circ}: \mathrm{I}$ - poderá ser diferenciado em função da região;II - devera ser estipulado de acordo com as aquisições anuais de matéria-prima efetuadas pelo produtor de Biodiesel. $3^{\circ} \mathrm{O}$ carimbo "Combustível Social” poderá, em relação ao produtor de biodiesel:

- conferir-lhe o direito a benefícios de políticas públicas específicas destinadas à promoção da produção de combustíveis renováveis, integrando a inclusão social e o desenvolvimento regional;II - ser utiliza- 
Além da exoneração fiscal, o selo «Combustível Social» é uma prévia condição para a participação nos leilões de compra de biodiesel da ANP e para a obtenção de melhores linhas de financiamento no Banco Nacional de Desenvolvimento (BNDS) e em outras instituições financeiras por parte de empresas ou de projetos de produção de biodiesel (NODARI, 2010, p. 57). Entretanto, para obter tais benefícios, é necessário adquirir porcentagens mínimas de matéria-prima proveniente da agricultura familiar, assumir um compromisso de adquirir uma produção com preços previamente determinados e cumprir as obrigações de prestações de serviçõs, a exemplo da assistência técnica aos agricultores (ASSIS; ZUCARELLI, 2007, p. 46).

Isso quer, portanto, dizer, que devemos seguir a porcentagem mínima de aquisição de matéria-prima de agricultores familiares, de acordo com a região em questão, de modo que a PNPB busque viabilizar a redução das disparidades regionais e sociais, princípio de ordem econômica previsto no art. 170 VII da Constituição da República. O assunto é também regulamentado por meio das Instruções Normativas do MDA, como no caso destes: $n^{\circ} 1 / 2005, n^{0} 2 / 2005, n^{\circ} 1 / 2009$ e $n^{0} 1 / 011$, que permitem aos agricultores familiares participar da cadeia de produção como parceiros

do para fins de promoção comercial de sua produção.

Art. $4^{\circ}$. Os coeficienes de redução diferenciados da Contribuição para o PIS/PASEP e o COFINS, previstos no $\S 1^{\circ}$ do $1^{\prime}$ art. $5^{\circ}$ da Lei n. 11.116, de 2005, permanecem fixados em:I - 0,8129 para o biodiesel fabricado a partir da MAMONA ou do fruto, do caroço ou da amêndoa de palmeira produzidas nas regiões Norte, Nordeste e no Semiárido;II - 0,9135 para o biodiesel fabricado a partir de matérias-primas que o agricultor familiar integrante do PRONAF colocará à disposição;III - 1,00 para o biodiesel fabricado a partir de matérias-primas produzidas nas regiões Norte, Nordeste e no Semiárido, provenientes da agricultura familiar abrangida pelo PRONAF. $\$ 1^{\circ} \mathrm{Com}$ a utilização dos coeficientes definidos nos incisos I, II et III do título deste artigo, aS porcentagens respectivas da contribuição ao PIS/PASEP e à COFINS que têm uma incidência sobre a receita bruta obtida pelo produtor por ocasião da venda do biodiesel, permanecem reduzidas em:I - R \$22,48 (vinte e dois reais e quaranta e oito centavos) e R \$103,51 (cento e três reais e cinquenta e um centavos), respectivamente por metro cúbico de biodiesel fabricado a partir de rícino ou do fruto, do caroço ou da amêndoa de palmeira produzidas nas regiões Norte, Nordeste e no Semiárido; - R \$10,39 (dez reais e trinta e nove centavos) e R \$ 47,85 (quarenta e sete reais e oitente e cinco centavos) respectivamente, por metro cúbico de biodiesel fabricado a partir de matérias-primas provenientes da agricultura familiar abrangida pelo PRONAF.III - R \$0,00 (zero), por metro cúbico de biodiesel fabricado apartir de matérias-primas produzidas nas regiões do Norte, Nordeste e Semiárido provenientes da agricultura familiar abrangidas pelo PRONAF.§ $2^{\circ} \mathrm{O}$ produtor de biodiesel, visando utilizar o coeficiente de redução diferenciada da qual tratam os incisos II e III do $\S 1^{\circ}$ deste artigo, deve ser detentor, em situação regular, da concessão de utilização do selo « Combustível Social » tratado no art. $2^{\circ}$ deste Decreto. $3^{\circ}$ No caso da aquisição de matérias-primas que permite a aplicação de taxas de abatimentos diferentes para a receita bruta proveniente da venda de biodiesel, as taxas de desconto das quais trata o $\S 1^{\circ}$ deste artigo devem ser aplicadas proporcionalmente ao custo de aquisição das matérias-primas utilizadas no período de referência.§ $4^{\circ}$ Naquilo que corresponde aos efeitos do $\S 3^{\circ}$ deste artigo, no caso da produção própria de matéria-prima, esta deve ser apreciada ao menor preço de aquisição de matéria-prima de terceiros, durante o período de referência. $\S 5^{\circ}$ As taxas de desconto deste artigo não se aplicam ás receitas provenientes da venda de biodiesel importado. 
ou associados das empresas ou por intermédio das associações ou cooperativas.

Nada impede que o «Selo Combustível Social» não seja utilizado para uma finalidade ambiental, diminuindo ou interditando a destinação de benefícios para as regiões que desejamos proteger, como é o caso de certas zonas do bioma amazônico ou de partes da caatinga ou do cerrado, já que o mesmo instrumento pode servir para estimular ou frear esta indústria. É inegável que isto não constituirá uma interdição, que não poderá ser decidido a não ser por meio de uma delimitação agroambiental adequada, consistindo em organizar a utilização e ocupação do solo, de forma administrativa e considerando a vocação natural do meio (MORAES, 2011, p. 85-86). O Decreto $n^{\circ} 4.297 / 2002$ regulamenta o artigo. $9^{\circ}$, II, da Lei $\mathrm{n}^{\mathrm{o}} 6.938 / 81$ e estabelece critérios par uma Cartografia EcológicoEconômica, cujo objetivo é o de «organizar, de forma obrigatória, as decisões dos agentes públicos e privados quanto aos planos, programas, projetos e atividades que, direta ou indiretamente, utilizam recursos naturais, assegurando, assim, a plena conservação do capital e dos serviços ambientais dos ecossistemas».

De fato, essa lei é avançada no que concerne às questões econômicas e sociais, principalmente se a comparamos à estrutura jurídica do álcool - biocombustível de melhor rendimento energético (SANTOS, 2013, p. 141), mas cujo sistema de produção em monocultura não permite a inserção de pequenos produtores. A esse respeito, a problemática ambiental deveria ter sido mais bem-observada, porque deveria haver aí um grande número de dispositivos legais mais efetivos. Trata-se de uma contradição inaceitável, uma vez que a comunidade internacional alertou sobre os impactos ambientais negativos do biodiesel e dos combustíveis em geral ${ }^{14}$ (SIRVINSKAS, 2009, p. 320). É necessário haver um cuidado todo particular com a monocultura, com o avanço dos biomas amazonenses e o cerrado, tanto quanto em relação à queda da agricultura familiar e à plantação de produtos alimentares (ASSIS; ZUCARELLI, 2007, p. 55) dentro de um contexto de segurança alimentar, o que deve constituir objeto de uma atenção especial sob a concessão de autorização ambiental

14 Dois estudos realizados na França, finalizados em 2012, confirmam a importância das mudanças de uso dos solos (CAS) ligadas ao desenvolvimento das culturas energéticas dos biocombustíveis na França e na União europeia e corroboram os estudos realizados pela Comissão europeia (CE). Apesar das dificuldades metodológicas para quantificar esse fenômeno, convém levar em conta os impactos dos CAS indiretos em face das políticas de desenvolvimento dos biocombustíveis (MINISTÉRIO DA ECOLOGIA, DO DESENVOLVIMENTO DURÁVEL E DA ENERGIA, 2013). 
(FARIAS, 2013, p. 41-45).

Se os benefícios ecológicos trazidos pelo biodiesel são evidentes, não significa que seus impactos ambientais devam ser ignorados pelos Poderes Públicos. Com efeito, é sintomático que nem a ANP, nem a CONAMA publicaram uma norma específica estabelecendo as referências de qualidade ambiental ou o regime de homologação ambiental do biodiesel. O problema é que, em face de um fato concreto, as administrações encarregadas do ambiente não poderão se basear em normas ou referências de qualidade ambiental, ligadas a outras matrizes energéticas existentes no país ou mesmo ao setor da agricultura, o que poderá causar certos prejuízos ao meio ambiente natural e à qualidade de vida da coletividade. Ou seja, mesmo que o biodiesel seja fortemente posicionado como uma evidência, em razão de sua dimensão ecológica, sua estrutura jurídica apostou prioritariamente nos aspectos econômicos e sociais em detrimento do meio ambiente. Agora, é necessário harmonizá-los.

\section{CONSIDERAÇÕES FINAIS}

Alterando a Lei $n^{\circ}$ 9.478/97, a Lei $n^{\circ} 11.116 / 05$ estabeleceu uma diferença jurídica específica para a produção e importação de biodiesel, embora ela se refira ao biocombustível de uma forma geral, em comparação a certos pontos. Esta lei permitiu que a cadeia de produção do biodiesel e dos biocombustíveis, de modo geral, seja regulamentada e, consequentemente, controlada e verbalizada pela ANP, cujas sanções administrativas são mais efetivas que as que foram aplicadas anteriormente pelo MAPA.

O maior avanço foi provavelmente o estabelecimento de uma porcentagem mínima obrigatória de acréscimo de $5 \%$ de biodiesel num espaço de oito anos. A prova é o fato de que desde $1^{\circ}$ de janeiro de 2010 , o óleo diesel nacional já contém $5 \%$ de biodiesel, fazendo do Brasil um dos líderes mundiais da fabricação e do consumo de biodiesel; o sucsso do PNPB é, portanto, evidente.

Se os benefícios ecológicos trazidos pelo biodiesel são evidentes, não significa que seus impactos ambientais devam ser ignorados pelos Poderes Públicos. Com efeito, é sintomático que nem a ANP, nem a CONAMA não esqueceram uma norma específica estabelecendo as referências de qualidade ambiental ou o regime de homologação ambiental do biodiesel. O problema é que, em face de um fato concreto, as administrações encarregadas do ambiente não poderão se basear em 
normas ou referências de qualidade ambiental, ligadas a outras matrizes energéticas existentes no país ou mesmo ao setor da agriculture, o que poderá causar certos prejuízos ao meio ambiente naturea e à la qualidade de vida da coletividade. Ou seja, mesmo que o biodiesel seja fortemente posicionado como uma evidência, em razão de sua dimensão ecológica, sua estrutura jurídica apostou prioritariamente nos aspectos econômicos e sociais em detrimento do meio ambiente.

Um regime fiscal específico foi adotado para o biodiesel, adotandose um modelo de cálculo e de taxa da contribuição do PIS/PASEP e da CONFINS sobre a receita bruta obtida pelos produtor ou importador. Para isso, a inclusão dos agricultores familiares e a prioridade dada às regiões mais pobres do país, a exemplo do Semiárido, é fundamental. É a razão pela qual um «Selo combustível social " foi instituído, condição prévia para poder concorrer nos leilões de biodiesel da ANP e para obter melhores linhas de financiamento por parte do BNDES e de outras instituições financeiras ${ }^{15}$. Os estímulos extrafiscais podem não se resumir somente ao plano da legislação nacional, mas, também, por meio de uma planificação urbana que adote as medidas de estínulo para sua produção, distribuição ou uso, num quadro de equilíbrio com as possíveis consequências perigosas para o meio ambiente, mesmo nas áreas rurais, inicialmente fora da competência do ordenamento urbano, uma vez que é preciso ter em conta, também, os efeitos de políticas públicas urbanas sobre os campos.

A falta de organização sindical dos agricultores é um problema grave, porque as políticas públicas são elaboradase executadas sema presença de representação coletiva operária, de modo que a participação social deixa a desejar. Os Poderes Públicos deveriam incitar mais efetivamente a criação de cooperativas de agricultores da cadeia de biodiesel. De outro lado, a problemática ambiental deveria igualmente ser incorporada à problemática social, sobretudo porque os pequenos agricultores não dispõem de meios para combater a degradação do meio ambiente. Seria interessante criar uma referência legal para os biocombustíveis em geral, que pudesse incluir também o álcool, e pudesse abordar a temática de maneira mais aprofundada e holística, seja sob uma perspectiva ambiental, seja sob um prisma do direito da cidade durável.

Embora sejam incorporadas à matriz energética brasileira, o fato é que a produção e utilização do biodiesel estão ainda em fase inicial, quando

15 Na França, os estímulos à promoção de energias renováveis podem ocorrer através de biocombustíveis pode ocorrer com a técnica da aprovação fiscal. (LQNDBECK, 2007, p. 1). 
as comparamos às expectativas existentes em relação a esse assunto. As incitações fiscais no nível dos Estados são tímidas e quase sempre tais políticas se limitam à criação de um programa ou de uma política e à instituição de um comitê ou de um conselho de gestão. Convém salientar que as maiores ajudas dos Poderes Públicos à produção de biodiesel são, de fato, de ordem econômica e social; a proteção ecológica não foi definida como uma prioridade, visto que nenhum dispositivo concreto foi efetivamente criado. Como dizia Aristóteles, a virtude está no meio.

\section{REFERÊNCIAS}

AGÊNCIA Nacional do Petróleo, Gás Natural e Biocombustíveis - ANP. Biodiesel - introdução. Disponível em: http:/www.anp.gov.br/pg=604 $68 \& \mathrm{~m}=\& \mathrm{t} 1=\& \mathrm{t} 2=\& \mathrm{t} 3=\& \mathrm{t} 4=\& \mathrm{ar}=\& \mathrm{ps}=\& \mathrm{cachebust}=1380352819981$. Acesso em: 28.jul.2013.

AGUIAR FILHO, Valfredo de Andrade. Regulação econômica ambiental: poder normativo entre Agência Nacional de Águas e a Agência Nacional do Petróleo. Tese de doutorado em Direito apresentada à Universidade Estácio de Sá. Rio de Janeiro, 2014.

ANTUNES, Paulo de Bessa. Direito ambiental. 14. ed. Rio de Janeiro: Lumen Juris, 2012.

ASSIS, Wendell Ficher Teixeira; ZUCARELLI, Marcos Cristiano. Despoluindo incertezas: impactos territoriais da expansão de agrocombustiveis e perspectivas para uma produção sustentável. Belo Horizonte: O Lutador, 2007.

BAUT-FERRARESE, Bernadette Le. Et MICHALLET, Isabelle. Traité de Droit des Énergies Renouvelables. Paris : Le Moniteur, 2008-2012.

COSTA, Maria D’Assunção. Marco regulatório do gás natural no Brasil. In: GONÇALVES, Alcindo; RODRIGUES, Gilberto Marcos Antônio (orgs). Direito do petróleo e gás: aspectos ambientais e internacionais. Santos: Editora Universitária Leopoldianum, 2007.

COSTA NETO, Pedro R.; ROSSI, Luciano F. S.; ZAGONEL, Giuliano F.; RAMOS, Luiz P. Produção de biocombustível alternativo ao óleo diesel através da transesterificação de óleo de soja usado em frituras. Química Nova, São Paulo, v. 23, n. 4, 2000. 
CUNHA, João Vidal da. Biodiesel e Lei 11.097/05 - impactos ambientais desconhecidos, impactos sociais relevantes. In: BENJAMIN, Antônio Herman; LECEY, Eládio; CAPPELLI, Silvia (orgs). Mudanças climáticas, biodiversidade e uso sustentável de energia. São Paulo: Imprensa Oficial, 2008, v. 2.

FARIAS, Talden. Licenciamento ambiental: aspectos teóricos e práticos. 5. ed. Belo Horizonte: Fórum, 2015.

FARIAS, Talden. Regulação dos biocombustíveis no âmbito estadual. In: FERREIRA, HelineSivini; LEITE, José Rubens Morato. Biocombustiveis: fonte de energia sustentável? Considerações jurídicas, técnicas e éticas. São Paulo: Saraiva, 2010.

FERREIRA, Ana Mônica Medeiros. Os instrumentos de incentivo à produção e uso de biodiesel no Brasil: uma análise constitucional sob o princípio do desenvolvimento sustentável. Mémoire de Master présentéauProgramme de 2ème cycleenDroit de l'UniversitéFédéraledu Rio Grande do Norte. Natal, 2010, p. 92-93.

GARCIA, Flávio Amaral; ROCHA, Henrique Bastos. Aspectos ambientais da lei do petróleo (Lei $n^{\circ}$ 9.478, de 6 de agosto de 1997). In: MORAES, Rodrigo Jorge; AZEVÊDO, Mariângela Garcia de Lacerda; DELMANTO, Fábio Machado de Almeida (coords). As leis federais mais importantes de proteção ao meio ambiente comentadas. Rio de Janeiro: Renovar, 2005.

INTERNATIONAL Energy Agency. World energy outlook 2007: China and India insights. Organisation for Economic Co-operation and Development/ International Energy Agency: Paris, 2007.

LEITE, Getúlio da Silveira; GUTMAN, José. O novo marco regulatório para as atividades de exploração e produção de petróleo e gás natural no Brasil. In: GONÇALVES, Alcindo; RODRIGUES, Gilberto Marcos Antônio (orgs). Direito do petróleo e gás: aspectos ambientais e internacionais. Santos: Editora Universitária Leopoldianum, 2007.

LEITE, José Rubens Morato. Dano Ambiental: do individual ao coletivo extrapatrimonial. 2. ed. São Paulo: Revista dos Tribunais, 2003.

LIMA, Haroldo. Petróleo no Brasil: a situação, o modelo e a política atual. Rio de Janeiro: Synergia, 2008. 
LQNDBECK, Dominique. Le régime juridiquedesbiocarburants, Revue d' Environnement et DevelopementDurable, n. 6, Juin 2007, étude 8, p. 1.

LONDON, Caroline. Énergie et environnement :uneéquationdifficile. Revue de 1'EnvironnementetDéveloppement Durable, n. 10, Octobre 2005, étude 30 .

LONGA, Dulce Conceição Pinheiro. Biocombustiveis: uma análise das políticas públicas. Dissertação de mestrado apresentada ao Programa de Regulação da Indústria da Energia da Universidade de Salvador. Salvador: 2008 .

MAIA, Lis Pereira. A regulação biocombustiveis para o desenvolvimento sustentável. Dissertação de mestrado em Ciências Jurídicas apresentada à Universidade Federal da Paraíba. João Pessoa, 2015.

MEIRELLES, Fábio de Salles. Biodiesel. Disponível em: http://www. forumdeenergia.com.br/nukleo/pub/biodiesel.pdf. Acesso em: 20.ago. 2013. Ministére de 1 'Ecologie, de leDevélopementDurable et de L'Energie. Bilancarbone des biocarburants :versuneprise en compte des changementsindirectsd'affectation des sols. 2013. Disponibleen : http:// www.developpement-durable.gouv.fr/Bilan-carbone-des-biocarburants. html. Acèssle 4 Juin 2015

MORAES, Rodrigo Jorge. Setor sucroalcooleiro: regimejurídico ambiental das usinas de açúcar e álcool. São Paulo: Saraiva, 2011.

NODARI, Rubens Onofre. Sobre os biocombustíveis: impactos, benefícios e alternativas. In: FERREIRA, HelineSivini; LEITE, José Rubens Morato. Biocombustiveis: fonte de energia sustentável? Considerações jurídicas, técnicas e éticas. São Paulo: Saraiva, 2010.

PROÁLCOOL - Programa Brasileiro de Álcool. Disponível em: http:// www.biodieselbr.com/proalcool/pro-alcool.htm. Acesso em: 20.jul.2009.

SABLIÈRE, Pierre. Droit de l'energie. Paris: Dalloz, 2014.

SALEME, Edson Ricardo; GIRÃO, Mardônio da Silva. In: BENJAMIN, Antônio Herman; LECEY, Eládio; CAPPELLI, Silvia (orgs). Direito ambiental, mudanças climáticas e desastres: impactos nas cidades e no patrimônio cultural. São Paulo: Imprensa Oficial, 2009, v. 1. 
SANTOS, Marisa Medeiros. A tutela jurídica da cana-de-açúcar como biocombustivel no direito ambiental brasileiro. São Paulo: Fiúza, 2013.

SILVA, Daiane Tessaro da; TRENTINI, Flávia. Biodiesel x sustentabilidade: um binômio possível? In: BENJAMIN, Antônio Herman; LECEY, Eládio; CAPPELLI, Silvia (orgs). Direito ambiental, mudanças climáticas e desastres: impactos nas cidades e no patrimônio cultural. São Paulo: Imprensa Oficial, 2009, v. 2.

SILVA, Henry Iure de Paiva. A temática ambiental como promotora de mudanças no sistema de relações econômicas internacionais: a hora e a vez dos biocombustíveis. Datavênia, Campina Grande, v. I, n 1, 2009.

SIRVINSKAS, Luís Paulo. Manual de direito ambiental. 7. Ed. São Paulo: Saraiva, 2009.

VERNIER, Jacques. Les énergies renouvelables. 6. ed. Paris: Presses Universitaires de France, 2012.

Recebido em: 09/08/2017. Artigo aceito em: 07/05/2018.

\section{Como citar este artigo (ABNT):}

FARIAS, Talden Queiroz; CORREIA, Arícia Fernandes. LE BIODIESEL DANS LE CONTEXTE JURIDIQUE BRESILIEN. Veredas do Direito, Belo Horizonte, v. 15, n. 31, p. 179-200, jan./abr. 2018. Disponível em: $\quad<$ http://www.domhelder.edu.br/revista/index.php/veredas/article/ view/1138>. Acesso em: dia mês. ano. 